\title{
On some fundamental methodological aspects in foresight processes
}

\author{
Michael Lauster ${ }^{1,2^{*}}$ (D) and Stephanie Hansen-Casteel ${ }^{1,2}$
}

\begin{abstract}
The question whether foresight processes are scientific procedures at all is still under lively discussion. In this article, we shall try to give an answer by creating a generic model of such processes and compare it to a widely accepted set of conditions characterizing scientific disciplines. The model developed here shows a similar structure, as some technology assessment procedure given by the German VDI, and is therefore one of the two major parts of a holistic approach to solving strategic decision problems. The detailed analysis will show how foresight fits to a fundamental model of sciences and reveals possible deficits and perils. Some recommendations are given for the development of quality assurance measures for foresight products. Special emphasis is laid upon the role of fallibilism and the applicability of Popper's mechanism of falsifying hypotheses.
\end{abstract}

Keywords: Foresight, Epistemology, Model of science, Quality assurance, Decision-making

"We do not know, we only guess."

-K. Popper-

\section{Introduction}

In a world of ever growing complexity, decision-making is a tough job. Countless possibilities arise when strategic problems are considered, especially taking into account decisions with long-term financial or personal consequences. Decision-makers with high responsibilities in politics, economics, or public affairs often do not or-with respect to principal considerations-cannot provide all the knowledge needed to found their decisions on a rational basis. So it is no wonder that assistance is increasingly sought from foresight processes pretending to bridge the gap between present and the not yet existing futures.

The higher the responsibilities are and the heavier the consequences weigh, the more trust must be laid in the advices derived from prognosis. The term "scientific," frequently taken as synonym for quality controlled

\footnotetext{
* Correspondence: Michael.Lauster@int.fraunhofer.de

${ }^{1}$ Institute for Technology Analysis and Foresight in the Field of Security Research, RWTH Aachen University, Aachen, Germany

${ }^{2}$ Fraunhofer Institut, für Naturwissenschaftlich-Technische Trendanalysen INT, Appelsgarten 2, 53879 Euskirchen, Germany
}

processes, is often used as a marketing argument for the products made by futurists of various proveniences.

But how trustworthy can such a product be and how scientific are foresight processes as a main output of futurism? Several scientific works deal with the theoretical underpinning of foresight processes, trying to set futurism into a scientific frame (e.g., $[3,6,10])$. Nevertheless, the question of scientificness within these processes is often unattended. In this essay, from an epistemological point of view, some methodological aspects will be discussed to show which parts of foresight processes are strictly based on scientific methods and at which points some more fundamental work is needed to assure the high-quality standards known from, e.g. physics or sociology.

\section{On the structure of foresight processes-a simplified, generic model $^{\mathbf{1}}$}

In principle, any foresight process-regardless whether political, sociological, technological or any other kind of topic is taken into account-consists of four separable phases, each coming with its own specific methodology. In a first step, these four phases will be described and, as a second step, will then be investigated with respect to the assumptions of the Minimal Epistemological Model of Science (MEMS, abbr. by the authors) together with the methodological features, both coined by Schurz [12]. 
Checking the phases against the MEMS will show whether foresighting is a scientific process at all.

The first and, probably, most important step of foresighting is-like in any scientific work-to properly define the problem in regard. Often, posing the right question already delivers the better part of the solution or, at least, shows a feasible way to derive answers.

Starting with a first version of the research question, the available knowledge related to the problem is gathered. This is a basic work common to all scientists. Especially in the historic disciplines, much emphasis is laid upon the choice of the respective sources, the critical discussion of facts and arguments found therein as well as the reflection of the cultural, political, and social circumstances under which arguments are made [7]. In the course of retrieving and understanding data, the necessity to sharpen or alter the research question may occur, creating new aspects for an extended search of further information. Phase I therefore often creates a hermeneutic cycle with iterative steps, leading to the final research question in regard and the related database for further investigation.

For foresight activities, this preparation phase is analogous to the one in historical sciences. However, there is one principle difference: no matter how far back in time the starting point of the investigation will go, the unconditional end will always be the present since foresight is a projection of present potentialities to a future point in time.

During phase II, the retrieved knowledge base is structured and the main possibilities and potentialities are identified. For this step, usually a multidisciplinary approach is needed. Even if we only focus on technology foresight, the variety of technologies requires a broad range of specialists able to judge actual achievements in their respective fields but also to find progresses in adjacent disciplines that might contribute to converging technology lines. If we broaden the view to consider aspects of sociological, economic, or political influences, we need to take into account an even wider spectrum of scientific disciplines. The result of a thorough sampling process will be a set of assumptions about possible trends and developments that might have important effects contributing to an imaginary future during the time span in regard. Thus, by stating the existence of observable trends and developments, testable hypotheses in Popper's sense are created. At least in principle, they can be tested against empirical facts by appropriate statistical methods.

During phases I and II, knowledge in the epistemological sense is derived. According to Plato's coarse but still useful definition, this means a convincing set of true and justified facts about reality [2]. The facts found refer to the present state of the observed sector of reality. There is an empirical background to justify these facts, and their truth can be checked via statistical test.

As will be shown in the further reasoning, there is a sharp boundary to the remaining two phases. Any extension of the knowledge base derived in the first two phases by projection of presently observable developments is a mere speculation. Whether such assumptions can be termed "scientific" at all will be discussed later on. However, a first statement can already be made: it is impossible to check the truth of these assumptions immediately in the sense of Popper's Critical Rationalism. ${ }^{2}$ Since they refer to a future point in time and because we have no signals or messages from the future in any way (something that runs backwards in time), the only possible check for truth is to wait until we reach the point in time to which the assumptions refer. But then, it is again the present we evaluate and not the future. As Popper coined it, there is a principle limit for knowledge: we cannot know what we shall know tomorrow because we then would already know it today [11]. The logical conclusion is that our epistemological knowledge exclusively reflects the present time and no way leads to knowledge about the future. ${ }^{3}$

However, facing the need to make strategic decisions with probably long-lasting consequences, one is forced to derive assumptions about possible future situations. This is done in phase III by projection processes applied to the knowledge base. The intermediate result will be one set or a number of alternative sets of parameters characterizing imaginary future states of reality. Each set corresponds to a specific situation (i.e., a "scenario") with its respective assumptions and boundary conditions (cf. e.g [14]).

For the sake of communicating these results to the decision-makers who are in general no experts for the question in regard, the main task will be to translate the parameter sets into an understandable text form. This is usually done in a narrative way. Like in phase I, in this step, the futurist works like the historian. While the latter tells a story from the past as he anticipates historic events indicated by literature and artifacts, the former imagines and describes future situations based on projected present evidences.

While the parameter sets described above will obey the principles of objectivity and intersubjectivity (in the sense of Schurz [12]), as a rule, the narrative created from it will strongly depend upon the researchers personal background even though he sticks to standardized methods and quality criteria given, e.g. in [4]. Additionally, there is a strong need to avoid specialized scientific codes and to use colloquial language. It is mandatory using a simple but clear way of storytelling in order to achieve comprehensive understanding and acceptance by the people addressed. Ambiguity should be limited by sticking closely to derived results and using logically consistent arguments. 
Thus, any imagination of future developments will create something we could term "present future", i.e., the picture of a possible future seen from today. It depends upon all our presently known facts, rules, norms, ideas, and even prejudices. Typically, this picture will differ from what actually will come true and what could be called the "future present"; sometimes (especially under the influence of "Wild Cards" or "Black Swans"), the differences will be significant. (Terms "present future" and "future present" are according to Grin und Grunwald [5]).

This gives rise to the question how such pictures, thoroughly derived with intricate methods but still false in general, could be of any use.

Phase IV provides the answer to this question: Future situations could (or will) be influenced by the solutions of the strategic decision problem. The pictures of possible futures derived in phase III will differ from the actually occurring future in some aspects; however, there is a strong belief that main effects of the problem are depicted and useful hints could be given to decision-makers.

Thus, the main task in this phase is the derivation of suitable recommendations related to the problem. They should enable decision-makers to make informed and rationally based decisions, help to foster preferable effects, and help to avoid undesirable aspects. Additionally, the way forward (e.g., in the form of a roadmap) into a desirable future could be the outcome of phase IV.
Depending upon the generated pictures of possible futures, new insights on the present situation will be derived. This could cause the need to feed back the outcome and to re-iterate the complete process until the "final" solution (which will always be intermediate and, as a rule, altered during implementation) is created.

Figure 1 depicts the four phases as a circular process. The hermeneutic cycle during phase I is symbolized by the curved arrow.

\section{The Minimal Epistemological Model of Science (MEMS)}

The question whether the procedure from chapter 2 may be termed "scientific" is still unanswered. This will be done by checking the complete process as well as the four phases separately against a set of widely accepted recommendations and conditions characterizing science. Since futurism in general and the foresight process described here is a multidisciplinary procedure, the requirements should be independent from specific disciplines.

The Minimal Epistemological Model of Science provides such a set consisting of five epistemological assumptions and four methodological features that can easily be compared to the course of action during foresight processes. A short description of the MEMS will suffice; further details may be looked up in [12].

The five key assumptions of the MEMS are (1) a minimal realism, (2) fallibilism and critical attitude, (3)

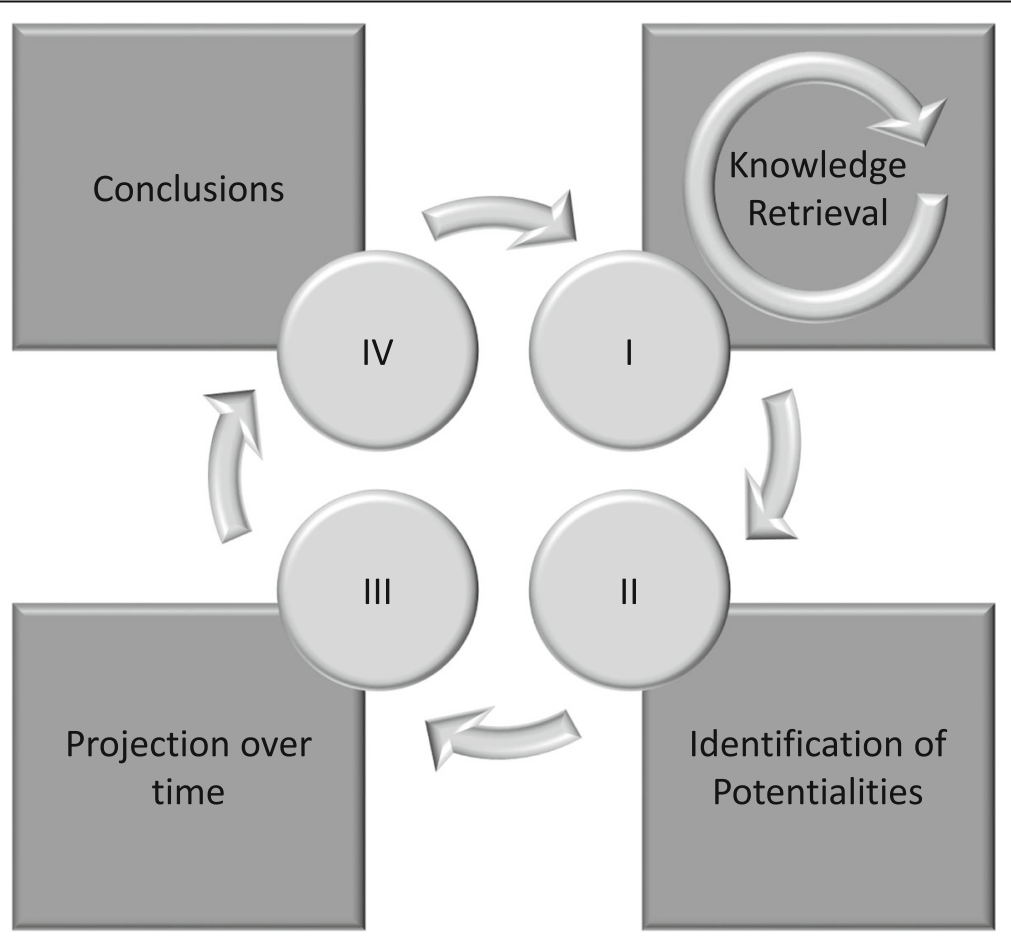

Fig. 1 Simplified model of foresight processes 
objectivity and intersubjectivity, (4) a minimal empiricism, and (5) logic in the wider sense. Although the model consists of a descriptive character, it is used as precondition of scientific discovery and is therefore considered as the normative framework of philosophy of science. Furthermore, it claims to be common to all empirical sciences in the broadest sense. The epistemological assumptions help to explain the possibility of objective science and will be described subsequently:

1. The notion of Minimal Realism stands for the assumption of an existing reality which is independent of the epistemological subject. Thereby, it is not assumed that all properties of this reality are knowable. The objective of scientific disciplines is to provide true, meaningful statements about clearly defined areas of this reality. The term truth here is understood in the sense of the correspondence theory: sentences are more substantial the more consequences-especially empirical consequences-they possess, thus referring to the pragmatic aspect of truth (cf. footnote 2).

2. Fallibilism and Critical Attitude pronounces that there is no privileged and secure way to truth in the above sense-neither through intuition nor any other "higher evidence." Every scientific statement is more or less fallible, and we can never be sure about its truth. Therefore, it is important to check every scientific hypothesis whether it is rather true (i.e., probabilistic and proven) or rather false and in extreme cases falsified.

3. According to Objectivity and Intersubjectivity, a statement has to be (a) objective: i.e., it needs to be independent of the epistemological subject's attitudes and prejudices. Reality has to be mapped by statements that are true and content rich. As this definition from objectivity by the scientific actors independency does not help in scientific practice, the second important criterion is that a statement has to be (b) intersubjective: i.e., if the truth of a statement can be convincingly substantiated, each person (assuming sufficient cognitive abilities) must be convinced of the truth of a statement in principle. Thus, intersubjectivity is understood as plausible consequence and indicator of objectivity and truth.

4. Minimal Empiricism indicates that the scope of science must be accessible to experience and observation because reliable information about reality can only be acquired by perceptual observation. Thereby, perception is the unique type of access to reality. Scientific law hypotheses and theories within empirical observations are the fundamental basis for truth. Empirical observations are not infallible but afford an easy and fast way to intersubjectivity and practical certainty. The general demand is that statements in the regime of theories must have observable consequences through which they can be tested.

5. Logic in the wider sense means that the application of logical methods (i.e., introducing and clarifying terms, formulating sentences precisely, and the construction of arguments) is the most effective way to achieve the goal of truth according to the assumptions $1-4$. Only for precisely formulated sentences, the logical consequences can be determined exactly-and only if this is the case, the sentences can be checked clearly and accurately. Furthermore, it is assumed that knowing the consequences of hypothesis and using exact logical methods is mandatory to test hypothesis empirically which requires the use of exact logical methods in the wider sense of logic and not in the sense of deductive logic.

Out of these five epistemological assumptions (1-5) and the epistemic goal, four methodological characteristics can be deduced. The primary epistemic goal is the discovery of true and meaningful sentences. That is, sentences must be not only true but also "rich in content" which means "empirically rich in content" and with regard to the problems which must be solved. Hereinafter, the four methodological features are described:

M1 is derived from the epistemic goal and specifies that science is looking for the most general and substantive hypotheses, laws, and theories that are recorded in scientific language. The concept of law includes both, deterministic and statistical laws (unlimited and limited).

M2 results from the assumption E4 and specifies that science searches for actual observation sentences that describe the results of observations, experiments, or measurements.

M3 specifies that science is used to declare actual observation sentences and to forecast potential observation sentences.

M4 specifies that science is used to test empirically its general and hypothetical sentences by comparing actual and potential observation sentences and to confirm or corroborate or to falsify or weaken the hypothetical sentence (law or theory).

M1 is necessary because laws and theories are examples of "empirically rich in content" sentences. In order to testify their truth, empirical data are needed, wherefore M2 is important. By means of this data, the sentences from M1 
can be compared by their empirical consequences (i.e., for their potential explanations and predictions). Therefore, steps 3 and 4 are necessary.

\section{Comparison of foresight processes to the MEMS}

In this chapter, the four phases of foresight processes will be checked against the five epistemological assumptions and the four methodological features as described in the section before. This will open the possibility to make a statement whether the processes are scientific, at which points care has to be taken to fulfill the conditions, and where emphasis should be laid upon to improve the methodology of foresighting.

Looking at phases I and II, we easily conclude that all conditions are valid for both phases except for E2 which is not true for phase I since no testable hypotheses are generated during information retrieval. Furthermore, only the identification of potentialities from the present state in phase II generates statements that are object to Fallibilism and Critical Attitude in the original sense. At no other point during the whole process, testable hypotheses are produced. It should be noted that Fallibilism is one of the major pillars the scientific method rests upon. In most disciplines, there is still no other widely accepted procedure to create knowledge, check hypotheses against reality, and improve theories by adding new features. Fulfilling this criterion in at least one phase of the process is mandatory to call it a scientific one.

Phase III seems to be the critical section of the process because only three out of nine conditions prevail:

Although the projections rest upon trends and developments with a real background, the results of the projection procedure refer to future points in time. They cannot be checked against any reality and thus do not fulfill the condition of Minimal Realism (E1). The same holds for E2 (Fallibilism and Critical Attitude) and E4 (Minimal Empirism) for the identical reason. Provided our assumptions from chapter 2 concerning present future holds, this is not really surprising. We already know that these fictional products will not exactly map the actually occurring future. All testing activities with regard to $E 2$ have been accomplished during phase II. Nevertheless, a critical attitude should always be considered even (or especially) during phase III. This will rather be a conceptual criticism as referred to in Shala [13] instead of an evidential criticism used in phase II [ibid.].

As was described in chapter 2, the narratives based upon the projected parameter sets will differ with the persons creating them. Lacking Objectivity and Intersubjectivity is prohibitive for condition $E 3$.

Only E5, the use of Logic in a Wide Sense holds for phase III, making only one out of five epistemological conditions to be fulfilled for this phase. Additionally, this recommendation seems to be so fundamental for any scientific process that it sounds quite trivial to demand as long as it stands alone for the epistemological part.

As far as the methodological features are concerned, the recommendations of $M 1$ and $M 3$ are met while no actual observations sentences (M2) can be obtained and empirical tests (M4) are impossible for future states in the classical way (i.e., by measuring present data).

Last but not least, even though phase IV does not generate testable hypotheses, but feeds back the findings from previous steps to the present state by giving hints and recommendations for the decision problem. Thus, all epistemological requirements including E2 are met as well as M4, provided both requirements are interpreted in a wide sense.

Table 1 shows these findings in a compact way. The numbers in the rightmost column and the last row give the sum of ticks in the checkboxes for rows and columns, respectively. The numbers may vary from 0 to 4 for the rows and from 0 to 9 for the columns.

From a global point of view it can be said that 26 out of 36 possible ticks are met. However, a careful analysis of the sums reveals some more detailed information.

First of all, none of the sums is zero, i.e., any of the four phases fulfills at least three out of nine conditions of the MEMS and, vice versa, any of the nine requirements is met by at least two phases.

Looking closer, we find that phases I and II have eight and nine ticks out of nine, respectively. It can be concluded that these two phases are the scientific basis of foresight procedures. In contrary, phase III fulfills only three conditions, with E5 including the least restricting one of all.

Looking at the requirements, E2 and M2 (which are interconnected) are only met in two phases. Since fallibilism and critical rationalism are the fundamentals of scientific work, this aspect should be examined very thoroughly.

Table 1 Comparison of the simplified foresight model to the MEMS

\begin{tabular}{llllll}
\hline & Phase I & Phase II & Phase III & Phase IV & \\
\hline E1 & $\checkmark$ & $\checkmark$ & - & $\checkmark$ & 3 \\
E2 & - & $\checkmark$ & - & $\checkmark$ & 2 \\
E3 & $\checkmark$ & $\checkmark$ & - & $\checkmark$ & 3 \\
E4 & $\checkmark$ & $\checkmark$ & - & $\checkmark$ & 3 \\
E5 & $\checkmark$ & $\checkmark$ & $\checkmark$ & $\checkmark$ & 4 \\
M1 & $\checkmark$ & $\checkmark$ & $\checkmark$ & - & 3 \\
M2 & $\checkmark$ & $\checkmark$ & - & - & 2 \\
M3 & $\checkmark$ & $\checkmark$ & $\checkmark$ & - & 3 \\
M4 & $\checkmark$ & $\checkmark$ & - & $\checkmark$ & 3 \\
& 8 & 9 & 3 & 6 & 26 \\
\hline
\end{tabular}




\section{Conclusions}

It goes without saying that for a classification of foresighting as scientific discipline, the complete process has to be considered. Looking at Table 1 globally, all nine conditions of the MEMS are fulfilled during the process. From this point of view, foresighting as represented by the simplified model given in section ${ }^{4}$ can be judged scientific in the sense of the MEMS.

A closer look at the inner structure of the process with its four phases reveals some details which give rise to a number of recommendations to be respected during foresight studies.

Phases I and II comply with all the aspects of the MEMS and are therefore the true scientific basis of the whole process. The remaining phases and especially the quality of the output-recommendations and helping advice for the decision-makers-rest upon it. Thus, in both phases, the rules and standards for good scientific practice should be applied very thoroughly to assure the veracity of the results. Since there is a close neighborhood to the science of history particularly in this part of the foresight process, recourse should be taken to the methods developed there for the search, selection, and critique of information sources.

Furthermore, the four phases take an individual point of view each. Phases I and II exclusively refer to past and present. On that basis, phase III looks in the positive direction of the time axis reaching out to possible futures. Phase IV, instead, reverses this view and looks from a possible future back to the present day, evaluating the actions that have to be taken to achieve (or to avoid) this future situation.

Figure 2 depicts this view on the foresight process:

Comprehensive investigation for information and careful evaluation of the contained possibilities are the basis of the pyramid. As to the temporal reference, it is the present which contains all available data. This opens the possibility to test the hypotheses on the potentialities created in phase II against an existing reality. It seems to be a feasible approach to let experts examine the set of hypotheses in an assessment like, e.g., a Delphi survey. The result will be a number of adjusted assumptions with reference to the present state of the respective aspect of reality.

The narrative phase rests upon this result and reaches out to a possible future. As can be seen from Table 1, this is the crucial part in terms of science with only three of nine conditions to be fulfilled. Especially, the epistemological part only complies with the demand for logic in a wide sense (E5). In contrary to this, seen from the decision-maker's point of view, the narrative is the most important part of the foresight process. It serves as an interface between the scientist and his customer. All the research conducted in phases I and II, usually taking weeks or months of work, have to be compressed to only

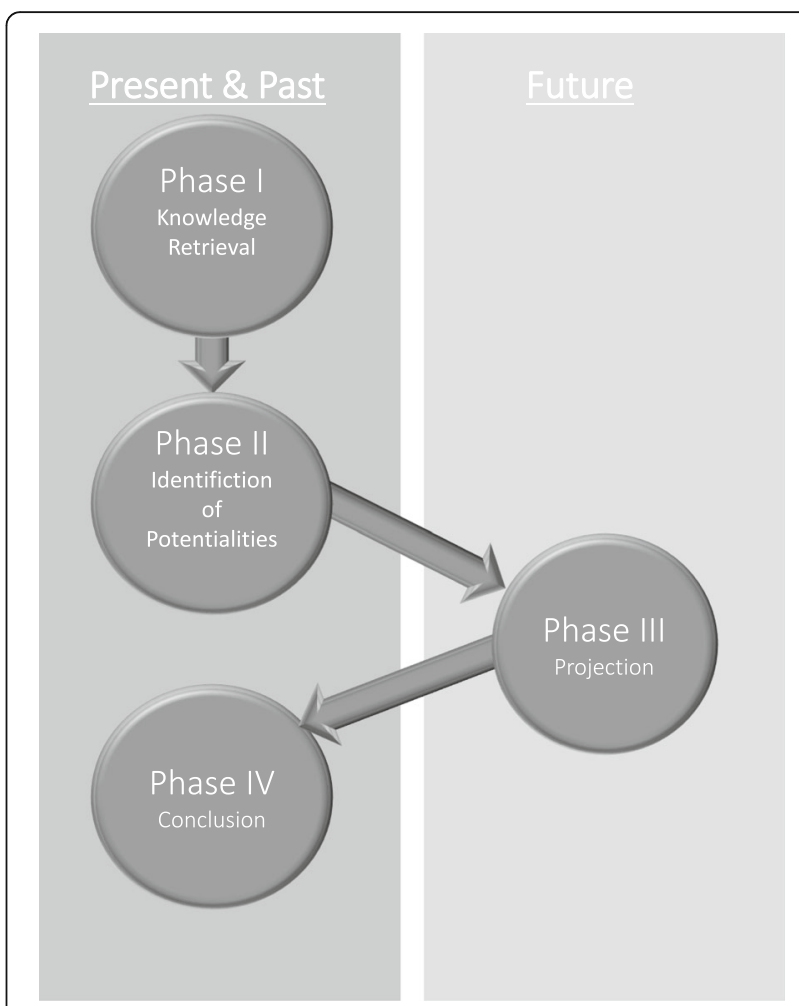

Fig. 2 Alternative view on the foresight process

a few pages of clearly understandable sentences. The narrative needs to be like a well-structured tale, consistent in its logic and attractive in its assumptions. Moreover, the aspects of the imagined future reality should be so easily to adopt that a decision-maker almost immediately will accept this future as a possible option. ${ }^{5}$ He should be able to integrate himself into these fictional worlds in order to answer his key questions in the whole process: "Given the fact that future worlds will be like this, what will be my role therein? And what are the conclusions for my present situation to achieve this future (or to avoid it)?"

There is a strong dependency of the narrative on the person creating it. One of the cardinal failures during this phase could be a biased logic inspired by certain ideas and opinions of the researcher. Additionally, there could be an (intended or unintended) tendency to influence the decisions of a customer in specific directions. This gives rise to a necessity of closely controlling this step. A comprehensive set of general rules and quality criteria should be created to give guide lines to the narrator. Several examples for such sets of rules have been published in the last years (cf. e.g., [8, 9]). However, the outcome of the narrative phase is a piece of literature in a certain way. It serves as the communication link between scientist and customer and is therefore of utmost importance. Therein, hard scientific facts worked out in the previous phases by experts have to be transferred into key statements 
understandable by and acceptable for usually non-expert decision-makers. The choice of words, the grammar, and the structure of the text differ in many ways from the textual products that are used to communicate scientific results amongst experts. Hints on how to produce literary product with high quality can be found in many text books, e.g., in Bowen et al. [1] and others.

Last but not the least, the same recommendations apply for phase IV. From the epistemological point of view, this phase meets all the criteria except for M1 to M3. Conclusions have to be logical in a wide sense and should be acceptable for the person addressed in terms of usefulness. Therefore, they have to be checked for their practical applicability against the (spatial, temporal, financial, etc.) background of the decision-maker. This is an even more crucial point than during phase III. Trying to find out the needs of the decision-maker by adopting his point of view bears a high danger of bias and adverse influencing. Special care should be taken to preserve objectivity and intersubjectivity in this step as far as possible.

\section{Summary}

A generic model of foresight processes has been created displaying the same structure as the technology assessment procedure proposed by VDI and therefore complements it in a natural way. Both processes could be regarded as two necessary parts of a holistic approach to strategic decision problems. The model comprises of four main phases with specific methodologies each.

This schematic process was compared to the Minimal Epistemological Model of Science (MEMS) with its nine conditions (five epistemological and four methodological ones).

Even though not every phase of this generic foresight process fulfills all nine conditions, it could be shown that foresighting is a scientific procedure in terms of the MEMS.

The analysis reveals that there are certain perils endangering the objectivity and intersubjectivity of the process. Therefore, a set of strong rules for quality assurance is required.

Several attempts to create such rules have been published lately but are still not common sense amongst the community. Further work has to be done to create a commonly accepted regime for the quality control of foresight products in order to tell scientific results from pure (non-scientific) speculation.

\section{Endnotes}

${ }^{1}$ This generic model for foresight processes shows a similar structure as the technology assessment process described in VDI Richtlinie 3730 Technikbewertung, Begriffe und Grundlagen 2000 [15]. Technology foresight is the necessary preceding step to technology assessment and complements, forming a holistic procedure to tackle strategic decision problems.

${ }^{2}$ In terms of the theory of truth, the concept used in this context is the notion of semantic truth. It is based on Tarski's definition of truth in formal languages. However, some aspects of the concepts of syntactic as well as pragmatic truth have to be taken into account since communicating scenarios via a narrative strongly relies on the acceptance by decision-makers. This will only be achieved if the story to be told follows a logical chain of thought (syntactical correctness) and the conclusions drawn from it are acceptable at least for the persons addressed (pragmatic aspect).

${ }^{3}$ Sometimes it is proposed to term scientifically derived projections in time as "knowledge about the future" or (short form) "future knowledge." We strongly recommend sticking to terms like "projection" or "scientific speculation" in order to avoid confusion with the sharply defined word "knowledge" from epistemology.

${ }^{4}$ This generic model for foresight processes shows a similar structure as the technology assessment process described in VDI Richtlinie 3730 Technikbewertung, Begriffe und Grundlagen 2000 [15]. Technology foresight is the necessary preceding step to technology assessment and complements, forming a holistic procedure to tackle strategic decision problems.

${ }^{5}$ These two recommendations refer to the syntactic and pragmatic aspects of truth as mentioned in footnote.

Authors' contributions

Both authors read and approved the final manuscript.

Competing interests

The authors declare that they have no competing interests.

\section{Publisher's Note}

Springer Nature remains neutral with regard to jurisdictional claims in published maps and institutional affiliations.

Received: 30 September 2017 Accepted: 21 June 2018

Published online: 11 July 2018

\section{References}

1. Bowen N, Meally M (2015) The art of writing English literature essays for A-level (and beyond). Revised \& expanded. Peripeteia Press; (Bowen und Meally 2015, England

2. Brendel, Elke: Wissen, De Gruyter, Berlin 2013

3. Cagnin C, Keenan M, Johnston R, Scapolo F, Barré R (2008) Future-oriented technology analysis. Springer-Verlag Berlin Heidelberg, Heidelberg

4. Gerhold L, Holtmannspötter D, Neuhaus C, Schüll E, Schultz-Montag B, Steinmüller K, Zweck A (2015) Standards und Gütekriterien der Zukunftsforschung. Ein Handbuch für Wissenschaft und Praxis. Zukunft und Forschung, Band 4, Springer, Wiesbaden

5. Grin J, Grunwald A (2000) Vision assessment. Shaping technology in 21st century society towards a repertoire for technology assessment. Springer (Wissenschaftsethik und Technikfolgenbeurteilung, Bd. 4), New York

6. Iden J, Methlie LB, Christensen GE (2017) The nature of strategic foresight research: a systematic literature review. Technological Forecasting \& Social Change, Volume 116, Pages 87-97, Elsevier March 2017

7. Jordan S (2013) Theorien und Methoden der Geschichtswissenschaft. 2., aktualisierte Aufl. Schöningh (Orientierung Geschichte, 3104

Geschichte), Paderborn 
8. Kuusi O, Cuhls K, Steinmüller K (2015) The futures map and its quality criteria. European Journal of Futures Research 3:22

9. Kuusi O, Cuhls K, Steinmüller K (2015) The topical collection on quality criteria for futures research: a short introduction. European Journal of Futures Research 3:21

10. Piirainen KA, Gonzales RA (2015) Theory of and within foresight- "What does a theory of foresight even mean?". Technological Forecasting \& Social Change, Volume 96, Pages 191-201, Elsevier July 2015

11. Popper KR (2013) Karl Popper, Logik der Forschung. 4., bearb. Aufl. Hg. v. Herbert Keuth. Akad.-Verl. (Klassiker auslegen, Berlin, p 12

12. Schurz G (2013) Philosophy of science. A unified approach. Routledge, New York

13. Shala, E. Eur J Futures Res (2015) 3:19. https://doi.org/10.1007/s40309-0150079-4

14. Steinmüller K (1997) Grundlagen und Methoden der Zukunftsforschung. Szenarien, Delphi, Technikvorschau. Sekretariat für Zukunftsforschung (WerkstattBerichte / Sekretariat für Zukunftsforschung, 21), Gelsenkirchen

15. VDI Richtlinie 3780:Technikbewertung, Begriffe und Grundlagen. BeuthVerlag, Berlin (2000)

\section{Submit your manuscript to a SpringerOpen ${ }^{\circ}$ journal and benefit from:}

- Convenient online submission

- Rigorous peer review

- Open access: articles freely available online

- High visibility within the field

- Retaining the copyright to your article

Submit your next manuscript at $\boldsymbol{\sim}$ springeropen.com 